\title{
Repensando a Questão da Cultura Política para os Regimes Democráticos Latino-Americanos ${ }^{1}$
}

\author{
Repensando la Cuestión de la Cultura Política para los Regímenes \\ Democráticos Latinoamericanos
}

\author{
Rethinking the Political Culture Question for Latin American Democratic \\ Regimes
}

Fábio Hoffmann²

\begin{abstract}
Resumo
Este trabalho propõe uma abordagem analítica sobre a democracia na América Latina diferente da convencional. Seu objetivo e distinção estão em procurar compreender os limites trazidos pela questão da cultura política no desenvolvimento democrático na região para além da epistemologia tradicional. Tal epistemologia depreende que tradições culturais da América Latina e os traços políticos nelas presentes perpetuam a fragilidade das democracias na região, uma vez que impedem que as instituições se consolidem e que o apoio ao sistema político atinja todas as suas dimensões de forma abrangente. Regimes e governos de países da América Latina sucumbem ou seguem esse caminho porque não conseguem entregar políticas públicas satisfatórias, e isso em grande medida por causa de uma capacidade de Estado limitada, uma cultura política híbrida e fragmentária. Com o apoio de evidências de dados do Variedades de Democracia (V-Dem 1990 - 2018) e Latinobarômetro, a proposta deste trabalho não é ir de encontro a essa tradição de pesquisa empírica, mas apontar seus limites e sugerir novos caminhos para se pensar a cultura política e a democracia em um contexto latino-americano de grandes desafios.
\end{abstract}

Palavras-Chave: América Latina; cultura política; democracia; epistemologia.

\section{Resumen}

Este trabajo propone un enfoque analítico sobre la democracia en América Latina diferente de la convencional. Su objetivo y distinción están en tratar de comprender los límites traídos por la cuestión de la cultura política en el desarrollo democrático en la región más allá de la epistemología tradicional. Tal epistemología depreende que las tradiciones culturales de América Latina y los rasgos políticos en ellas presentes perpetúan la fragilidad de las democracias en la región, ya que impiden que las instituciones se consoliden y que el apoyo al sistema político alcance todas sus dimensiones de forma integral. Los regímenes y gobiernos de países de América Latina sucumben o siguen ese camino porque no logran entregar políticas públicas satisfactorias, y eso en gran medida debido a una capacidad de Estado limitada, una cultura política híbrida y fragmentaria. Con el apoyo de evidencias de datos de Variedades de Democracia (V-Dem 1990 - 2018) y Latinobarómetro, la propuesta de este trabajo no es ir en contra de esa tradición de investigación empírica, sino apuntar sus límites y sugerir nuevos caminos para pensar en la cultura política y la democracia en un contexto latinoamericano de grandes desafíos.

Palabras claves: América Latina; cultura política; capacidad de Estado; democracia; epistemología.

\footnotetext{
1 Artigo apresentado no Simpósio Temático Repensar, Refletir, Interpretar e reinterpretar a Memória, Identidade e o Patrimônio Cultural da América Colonial durante o II Seminário Latino-Americano de Estudos em Cultura SEMLACult em Foz do Iguaçu/PR, Brasil, 2018.

${ }^{2}$ Mestre em Ciência Política pela Universidade Federal de Pelotas - UFPEL, Porto Alegre, Rio Grande do Sul, Brasil.E-mail: molahms@gmail.com.
} 


\begin{abstract}
This paper proposes an analytical approach to democracy in Latin America, different from the conventional one. Its aim and distinction are to seek to understand the limits brought by the question of political culture in the democratic development in the region beyond the traditional epistemology. Such an epistemology implies that Latin American cultural traditions and the political traits in them perpetuate the fragility of democracies in the region, since they prevent institutions from consolidating and that support for the political system reaches all its dimensions comprehensively. Regimes and governments of Latin American countries succumb to or follow this path because they fail to deliver satisfactory public policies, largely because of limited state capacity, a hybrid, fragmentary political culture. With the support of data from the Varieties of Democracy (V-Dem 1990 - 2018) and Latinobarómetro, the proposal of this paper is not to go against this tradition of empirical research, but to point out its limits and suggest new ways of thinking about culture and democracy in a Latin American context of great challenges.
\end{abstract}

Keywords: Latin America; political culture; State capacity; democracy; epistemology.

\title{
1. Introdução
}

Max Weber (1981, p. 23) fez referência ao provérbio "coma ou durma bem”, “o protestante prefere saciar-se, e o católico dormir sem ser perturbado", disso se presume que a busca de uma vida mais tranquila sempre fora o principal alvo das atenções da ética católica. A formação cultural dos países de tradição católica, quando comparados aos de tradição protestante, argumenta Inglehart e Welzel (2009), são de ordem mais vertical, o que atrapalha o desenvolvimento da confiança horizontal, tão necessária a prosperidade dos negócios e a queda da hierarquia, presentes numa sociedade democrática.

$\mathrm{Na}$ América Latina a ordem política sucedeu a liberalização da participação, argumentou Samuel Huntington (197) fazendo alusão de que a inexistência de instituições consolidadas, com autoridade e ordem suficiente para guiar suas nações, a democracia seria um equívoco, pois a instabilidade seria a sua marca. O’Donnell, Schimitter e Whitehead (1988) argumentaram que, na maioria dos casos, a democracia na América Latina foi o resultado de pactos verticais feitos entre elites e setores militares, o que fez com na sua gênese, ela retivesse essa natureza tutelada.

Estes argumentos apontados acima constituem parte da agenda hegemônica que procura entender a relação entre cultura política e democracia. O discurso dominante aponta que fragilidades e especificidades da cultura política na América Latina concorrem para a instabilidade política na região, uma vez que impedem que a burocracia se especialize e o Estado se fortaleça, a confiança se amplie e atinja amplos níveis de apoio ao sistema político. Enfim, comparada com suas congêneres do Norte, as democracias latino-americanas estariam fadadas ao atraso e a instabilidade. No entanto, caracterizações como populismo e a volta do nacionalismo com características xenófobas em democracias consolidadas pressionam pela 
abertura do discurso científico dominante e a ampliação da agenda de pesquisas do campo epistemológico tradicional.

Qual o alcance explicativo da cultura política para a instabilidade da democracia na América latina? Esta é a questão de fundo do presente trabalho, uma vez que teorias explicativas tradicionais como da cultura política, desenvolvimento econômico e pósmaterialismo mostram-se insuficientes para uma realidade cada vez mais complexa. Cada vez mais presentes em nações com democracias consolidadas, fenômenos como populismo e nacionalismo deixaram de ser características apenas de países com sociedades "atrasadas" e passam a preocupar pesquisadores exportadores e fortalecedores da epistemologia da agenda dominante.

O artigo está estruturado da seguinte forma: em um primeiro momento trazemos uma breve contextualização da relação entre cultura política e democracia baseada em obras clássicas de formação desse campo, trazendo a descrição e argumentação para o contexto latino-americano, onde destacamos a gênese dos Estados latino-americanos e o tipo de cultura política formada, a importação do modelo de democracia liberal, e a capacidade de Estado apresentada pelos países da região; em seguida nos envolvemos na questão de estarmos ou não condenados a um eterno atraso quando levamos em consideração os alcances e limites da literatura dominante; na sequência é feito um esforço para repensar a cultura política para as democracias latino-americanas a partir dos problemas então expostos; por fim, a conclusão traz a síntese, bem como questões que podem suscitar futuras reflexões e pesquisas que, por sua complexidade, não puderam ser abordadas no escopo deste trabalho.

\section{Cultura política e democracia na América Latina}

A procura de uma relação entre cultura política e democracia é antiga, no entanto, a composição da agenda moderna da tradição de pesquisa nos remete a duas obras centrais: A Democracia na América de Aléxis de Tocqueville ([1835], 1987) e The Moral Basis of Backward Society de Edward Banfield (1958). Enquanto a primeira obra se refere a percepção de gênese de uma nova sociedade nos Estados Unidos da América no século XIX, a segunda constitui um apelo mais moral e normativo quanto ao tipo de cultura específica encontrada na Itália de meados do século XX. No entanto, embora Tocqueville e Banfield constituam referências essenciais, foi com The Civic Culture de Gabriel Almond e Sidney Verba (1966) que a cultura política encontraria na democracia um tema para uma agenda mais ampla de pesquisa empírica. 
A pedra fundamental lançada por Almond e Verba levou a formação de uma agenda de pesquisas nas quais se buscariam fatores e elementos explicativos para justificar a ocorrência da democracia em certos países. Explorando dados de pesquisas surveys realizadas nos Estados Unidos, Alemanha, México, Itália e Reino Unido, Almond e Verba concluíram estas sociedades apresentavam três tipos de cultura política: participativa, súdita e paroquial. Enquanto que na primeira havia um bom envolvimento das pessoas com a vida social e política de suas comunidades, quando transitamos do segundo tipo para o terceiro este interesse ia diminuindo. A cultura política participativa era encontrada nas sociedades democráticas, principalmente Estados Unidos e Reino Unido, enquanto que os outros países pesquisados transitavam entre uma sociedade de tipo súdita ou paroquial.

O elemento explicativo central para a formação de uma cultura política participativa se encontrava no protestantismo. A alusão era de que, historicamente, as instituições religiosas protestantes ajudam a promover o que Weber (1981) denominou de "ética protestante". Baseados na tradição do trabalho, família e religião, os protestantes além de promover o que o autor denominou de os "alicerces" do capitalismo, também contribuíram para desenvolver níveis elevados de confiança interpessoal e um alto grau de pluralismo cultural. Todos esses fatores concorreram para que a industrialização tenha "ocorrido nos países protestantes mais cedo do que no restante do mundo" (Inglehart; Welzel, 2009, p. 99).

$\mathrm{O}$ argumento normativo era claro: enquanto sociedades que assumiram o protestantismo, trabalhavam, oravam e tinham na família um eixo social estruturante prosperaram e se democratizaram, outras que não seguiram o mesmo caminho encontravam dificuldades de desenvolver suas economias e ter um regime político democrático estável, ou seja, sociedades católicas como as da América Latina, tribais como as africanas e confuncianas como as asiáticas. Para os países latino-americanos, por exemplo, a cultura política formada traz traços como clientelismo, patrimonialismo e populismo, elementos forjados pelo desenvolvimento de Estados tardios e verticais que, associados a uma sociedade de tradição católica, acaba gerando uma incapacidade de institucionalização política que uma democracia estável requer.

Três são os argumentos centrais que exploraremos a seguir: a formação do Estado e das sociedades latino-americanas e o tipo de cultura política formada com características de hibridismo, fragmentária e, portanto, resultando, portanto, numa democracia inercial; o da importação dos modelos liberais de democracia pelos países da América Latina; e por fim, o da capacidade de Estado. Este último, embora também possa constituir parte do primeiro argumento, procuramos analisá-lo de forma separada, entendendo que há a existência, 
igualmente, de um viés normativo. Estes argumentos constituíram, embora não exclusivamente, grande parte do eixo da agenda de pesquisas sobre cultura política na América Latina, e o que podemos considerar, também tem contribuído para uma dependência epistemológica ainda muito forte (Silva; Baltar; Lourenço, 2018).

\subsection{Cultura política híbrida, fragmentária e a tese da democracia inercial}

Grande parte da literatura dá destaque ao fato da América Latina fazer parte de uma zona cultural que carrega consigo traços e valores que, em grande medida, não determina, mas condiciona a direção da sua evolução. Ela é católica e foi colonizada de forma exploratória em sua maior parte por espanhóis ou portugueses. O impacto das tradições religiosas no desenvolvimento econômico e político já foram ressaltados por Weber (1981) e Huntington (2002) e Landes (2002). Inglehart e Welzel (2009) igualmente reforçaram que dois fatores históricos são importantes para entender o desenvolvimento econômico, político e social dos países: sua tradição religiosa e suas histórias coloniais.

Historicamente, as instituições religiosas protestantes ajudam a promover o que Weber (1981) denominou de "ética protestante". Baseados na tradição do trabalho, família e religião, os protestantes além de promover o que o autor denominou de os "alicerces" do capitalismo, também contribuíram para desenvolver níveis elevados de confiança interpessoal e um alto grau de pluralismo cultural, todos esses fatores concorreram para que a industrialização tenha "ocorrido nos países protestantes mais cedo do que no restante do mundo" (Inglehart; Welzel, 2009, p. 99).

Já nas tradições católicas, o caso da América Latina, ao contrário, o impulso de aquisição sempre fora condenado, a busca de uma vida mais tranquila sempre fora o principal alvo das atenções da ética católica, de acordo com esse argumento e como distingue Max Weber em referência ao provérbio "coma ou durma bem": "o protestante prefere saciar-se, e o católico dormir sem ser perturbado" (Weber, 1981, p. 23). Mas não é só o desenvolvimento econômico que a tradição religiosa católica minaria, ela também impediria o desenvolvimento dos laços sociais horizontais, por se apresentar sempre de forma hierarquicamente vertical, e altamente centralizada.

A gênese do Estado também ajuda a entender a formação e a relação da sociedade com o Estado. Outro argumento que surge é o de que a América Latina fora explorada através da obra de expansão mercantilista portuguesa, espanhola e, em menor medida, holandesa e francesa. Diferente dos Estados europeus que percorreram um longo caminho de concentração 
da coerção e do capital (Tilly, 1996), os Estados latino-americanos foram formados sem antes de neles haverem sociedades.

As grandes extensões de lavoura e a necessidade de uma mão de obra abundante levou a disseminação do recurso da escravidão. A prática da escravidão em grandes extensões de terra condicionaria a outros fenômenos, como o caudilhismo e os regimes oligárquicos. Diante de uma sociedade desorganizada, maciçamente analfabeta e dependente ganha contorno dois traços característicos da região: o personalismo e o clientelismo político. Nesta tradição de pensamento, o patrimonialismo sempre estivera presente nessas sociedades, desde sua distribuição territorial para fins de exploração. Em nome do desenvolvimento político, entendia-se a atuação institucional como parte do instrumento pessoal do líder político, seja para obter riqueza, ou também prestígio e poder. E à medida que os países latino-americanos fomentaram suas industrializações, com os processos de substituição das importações, a urbanização se acentua sobre uma sociedade até então, muito desorganizada. O populismo, nesta visão, surgiria como fenômeno para manobrar essa massa ainda dispersa, deixada levar pelo carisma de um líder ou suas qualidades distinguíveis.

De acordo com Baquero (1998) estes fatores acabaram por formar uma cultura política híbrida em países da América Latina que tinham um passado comum de exploração econômica e de formação de Estados a partir de decisões da Metrópole. Uma cultura política híbrida que mistura importantes avanços em sua dimensão procedimental ao mesmo tempo em que mantém atrasos em sua dimensão social. Os avanços na dimensão procedimental são as eleições periódicas com amplo sufrágio, competição política através da garantia de espaço institucional para que lideranças de oposição busquem o poder, enquanto que em sua dimensão social se perpetuam sérios problemas de garantia dos direitos civis, políticos e sociais, fragilidade do Estado de direito, e uma cultura política paroquial e com baixo empoderamento. Tal configuração levou Baquero (2013), a denominar os regimes políticos da América Latina de democracias inerciais.

Castro (2014) incorporou à suas análises variáveis de natureza econômica e social, e chegou ao entendimento de que o tipo de cultura política formada em países como Argentina, Brasil e Chile (mas que pode ser estendida aos demais países da América Latina) é fragmentária, ou seja, diante de um contexto de enorme desigualdade, as pessoas são incapazes de discernir que seus problemas individuais se confundem com os problemas sociais, ao mesmo tempo em que não compreendem como os fenômenos políticos e econômicos os afetam de forma direta e indireta, transformando suas realidades cotidianas. 
Importante destacar que traços como o personalismo, clientelismo, patrimonialismo e populismo sempre estiveram presentes em graus variados na prática política dos países latinoamericanos. Todos eles impõem sérias restrições à institucionalização democrática uma vez que fazem das instituições meros instrumentos para o alcance de fins pessoais. Mas se antes o argumento trazido pela epistemologia tradicional era de que estes fenômenos constituiriam exclusividades de países com desenvolvimento econômico tardio, hoje, uma vez que democracias consolidadas e ricas passaram a apresentar estes mesmo problemas, o argumento perde validade ou pelo menos parte de seu potencial explicativo, pois que há uma realidade completamente nova demandando pesquisas e ferramentas conceituais mais abrangentes.

O agravo da crise contemporânea do modelo liberal de democracia pode estar na razão de que suas sociedades têm pressionado cada vez mais seus regimes por responsividade. As aspirações e demandas se transformaram rapidamente enquanto o arcabouço institucional da democracia representativa não conseguiu acompanhar essa evolução. Portanto, os elementos da alegada instabilidade política presente nos regimes democráticos em países da América Latina deve ser relativizada quando tiver como única causalidade a cultura política. $\mathrm{O}$ argumento da cultura também nos remete ao do transplante do modelo liberal de democracia para países latino-americanos.

\subsection{América Latina e a importação dos modelos de democracia liberal}

Este argumento faz alusão ao fato de que os Estados latino-americanos foram antes uma imposição das metrópoles mercantilistas em suas novas formas de alavancarem suas economias, que uma formação e evolução institucional política de suas sociedades. A partir de Estados transplantados, os países da América Latina importaram ou inspiraram-se nos principais modelos de democracias ocidentais como os Estados Unidos, França e Inglaterra para a formação de seus sistemas políticos.

O processo histórico que culminou nos arranjos democráticos dos países ocidentais no norte, no entanto, é muito distinto do que levou a democracia aos países da América Latina. Enquanto no norte a formação do Estado Nacional levou ao surgimento de instituições representativas aristocráticas, que foram se democratizando em um processo intenso de luta social por ampliação de direitos civis e políticos (Tilly, op. cit.), na América Latina, ao contrário, se criaram "dinâmicas órfãs" (Badie; Hermet, 1993), com estruturas estatais transplantadas, e com instituições representativas que, ao longo das suas histórias, jamais foram submetidas a uma pressão por parte da sociedade para que democratizassem. Este argumento decorre do fato de que na América Latina, as instituições foram criadas sem antes 
nelas haverem lastros sociais fortes, ou seja, elas não surgiriam da pressão de uma sociedade que aos poucos estaria se organizando e pressionando pela vazão de suas demandas e aspirações, mas sim, de formas verticais, de cima, do Estado para uma sociedade dispersa e não o contrário.

A democracia na América Latina em maioria dos casos foi o resultado de pactos verticais (O’Donnell; Schmitter; Whitehead, 1988) feitos entre elites e setores militares, o que fez com na sua gênese, ela nascesse regulada. As pressões que as instituições representativas das democracias consolidadas sofreram ao longo de seu processo evolutivo por parte da sociedade foram importantes para seu grau de institucionalização. Hoje, no entanto, elas vêm passando por uma crise constante, e umas das razões centrais é que não mais estão conseguindo se constituírem em canais legítimos de representação para essa sociedade que desponta de uma realidade mais complexa.

Como argumentado, as instituições das democracias latino-americanas, historicamente, não se legitimaram a partir de pressões canalizadas por parte da sociedade, e hoje enfrentam o seguinte dilema: na ausência de um grau razoável de institucionalização estão tendo que enfrentar aspirações e demandas sociais em rápida agitação pressionando por soluções urgentes e legítimas. É por esse motivo que a crise da democracia liberal afeta em um maior grau as democracias da América Latina em seu modelo importado. Consequentemente, os traços apresentados acima constituintes da cultura política na região são elementos importantes a serem considerados em análises mais expandidas. $\mathrm{O}$ gráfico 1 , com dados do Variedades de Democracia (V-Dem) $)^{3}$, diz respeito a alguns aspectos da institucionalização da democracia liberal na América Latina.

\footnotetext{
${ }^{3}$ O Variedades de Democracia (V-Dem) é uma ferramenta que mede a democracia em suas dimensões eleitoral, liberal, participativa, deliberativa, igualitária, majoritária e consensual, através de uma colaboração de mais de 50 estudiosos em todo o mundo. É co-organizado pelos departamentos de Ciência Política da universidade de Gotemburgo (Suécia) e o Instituto Kellogg da Universidade de Notre Dame (EUA). Sítio: https://www.vdem.net/en/.
} 


\section{Gráfico 1}

Índice de democracia liberal nas Américas ${ }^{4}$

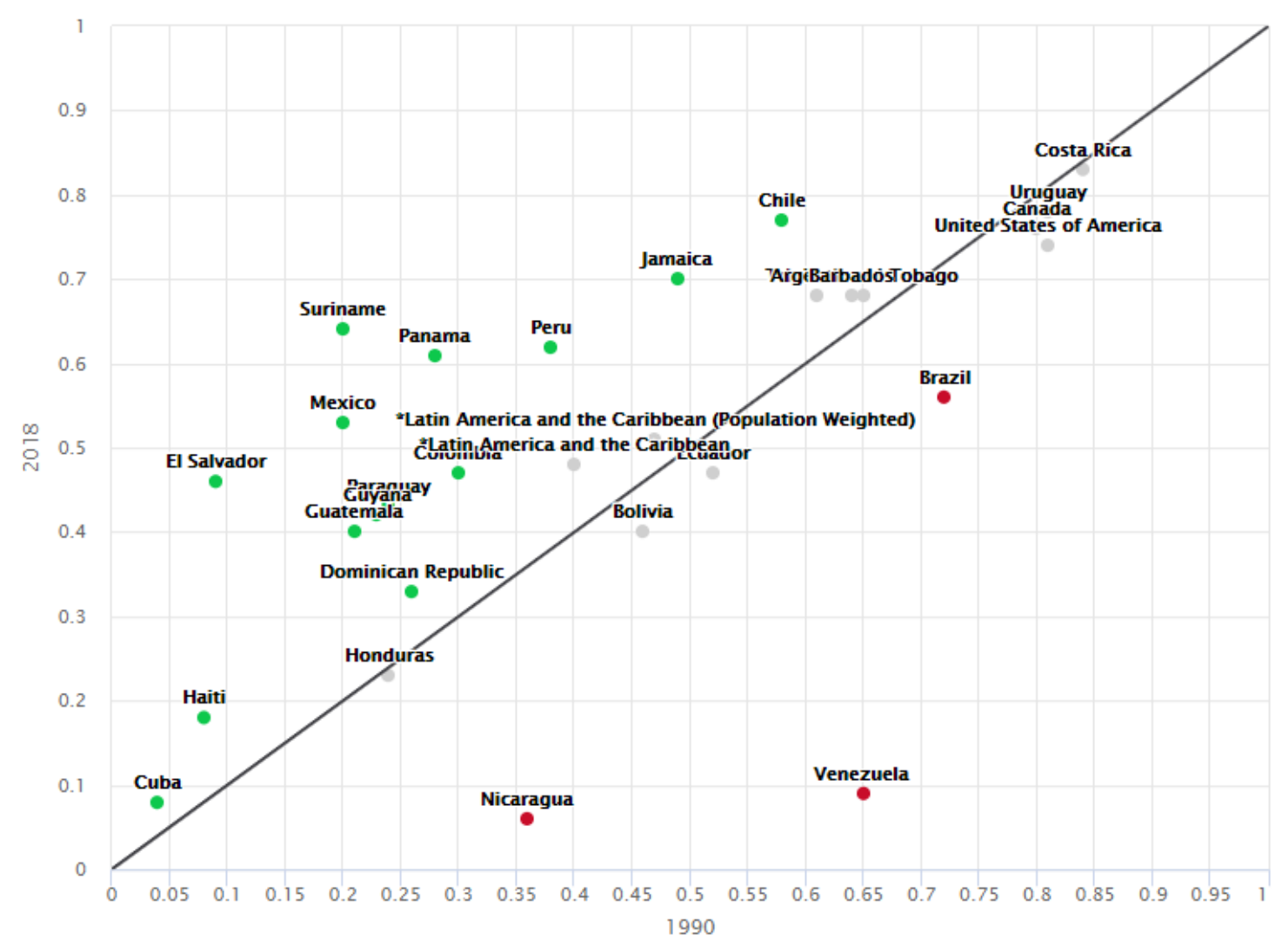

Fonte:

Variedades de democracia $(1990-2018)$.

A escala de 0 a 1 retrata o posicionamento dos países da América quanto ao índice de democracia liberal. A Venezuela apresenta o pior caso de deterioração do índice, uma vez que em 1990 apresentava 0.65, e em 2018 encolheu para apenas 0.09. Na outra ponta, a Costa Rica desponta como a democracia mais estabilizada da região, com índice de 0.84 em 1990 e 0.83 em 2018. Estados Unidos regrediram de 0.81 em 1990 para 0.74 em 2018. Brasil apresenta queda ainda mais impressionante, caindo de um índice de 0.72 em 1990 para 0.56 em 2018. Costa Rica e Uruguai são os países latino-americanos onde a institucionalização democrática apresenta melhores índices.

Contudo, apesar do caminho parecer mais tortuoso para a institucionalização da democracia na América Latina, essa dificuldade não pode justificar-se apenas no fato da trajetória institucional latino-americana não ter seguido o caminho linear da sociedade para o Estado. Este argumento encontra amparo no fato de que democracias consolidadas têm

\footnotetext{
${ }^{4} \mathrm{O}$ índice de democracia liberal do V-Dem leva em conta alguns componentes como: eleições livres, amplas e idôneas; lugar institucionalizado para a contestação política; predomínio do Estado de direito; liberdades civis e políticas; cortes judiciais independentes com verificações e balanços eficazes.
} 
apresentado problemas similares, portanto, uma nova explicação mais abrangente deve ser a demanda central de uma agenda de pesquisas expandida. Partimos, por conseguinte, para o argumento da capacidade de Estado.

\subsection{Capacidade dos Estados Latino-Americanos}

Outro fator explicativo que ganhou penetração na agenda de pesquisas da cultura política e até mesmo na agenda institucional ou neoinstitucional é o da capacidade do Estado como instrumento importante para compreender a democratização, consolidação e qualidade do regime. Tilly (2013) chama a atenção para o fato de que nenhuma democracia pode funcionar se o Estado não possui a capacidade de programar, implementar e supervisionar as decisões realizadas através dos processos políticos públicos.

Pippa Norris (2012) entende que a capacidade do Estado está diretamente ligada à qualidade da democracia, e a distinguiu baseada em duas dimensões weberianas: a primeira é o Estado como detentor do monopólio legítimo da violência e sua competência para garantir a segurança e Estado de direito (rule of law), garantindo o império da lei (enforcement of law); a segunda é a qualidade do corpo burocrático para entregar bons serviços, a partir de características como meritocracia, plano de carreira avançado, independência das pressões que a conjuntura política fomenta, e controle da corrupção.

Fukuyama (2015) argumenta para a presença de uma incapacidade de institucionalização do Estado em democracias da terceira onda (as latino-americanas), onde estas, por sua vez, não têm conseguido atender a crescente demanda popular por accountability democrática. No caso da América Latina, como afirmamos, a análise dessa dimensão não pode ser dissociada da questão cultural, onde os resquícios de um passado colonial caudilhista e escravocrata continuam a intrometer-se no futuro dos países.

Steven Levistky (2018) tem considerado que um dos fatores que contribuem para a crescente insatisfação popular com o regime democrático é a fraqueza de seus Estados. Para ele, Estados latino-americanos têm dificuldade em taxar efetivamente e combater a desigualdade econômica e social estrutural. Sem agências eficazes e com uma burocracia desqualificada, é apenas uma questão de tempo para que governos deixem de possuir uma confiança pública e institucional necessária.

De acordo com os dados do Latinobarômetro ${ }^{5}$ de 2017 , mais de $65 \%$ dos latinoamericanos estão insatisfeitos com a democracia em seus países, apesar de mais de $70 \%$

\footnotetext{
5 A Corporação Latinobarômetro é uma ONG com sede na cidade de Santiago, no Chile, que investiga o desenvolvimento da democracia, da economia e da sociedade como um todo em países da América Latina,
} 
responderem que a democracia é a ainda melhor forma de governo. Quando perguntados se tem havido progresso no combate a corrupção, mais de $60 \%$ dizem que pouco ou nada tem sido feito, e quando a pergunta se volta para questões como funcionamento do sistema judicial, dos hospitais e transporte público, mais da metade (50\%), dizem estar insatisfeitos com esses serviços. Em suma, na percepção da população latino-americana, portanto, os governos de seus países não tem conseguido entregar a eles serviços públicos de qualidade. $\mathrm{O}$ gráfico 2, também com dados do Variedades de Democracia (V-Dem) vemos alguns elementos do Estado de direito de países da América.

\section{Gráfico 2}

Estado de direito nas Américas ${ }^{6}$

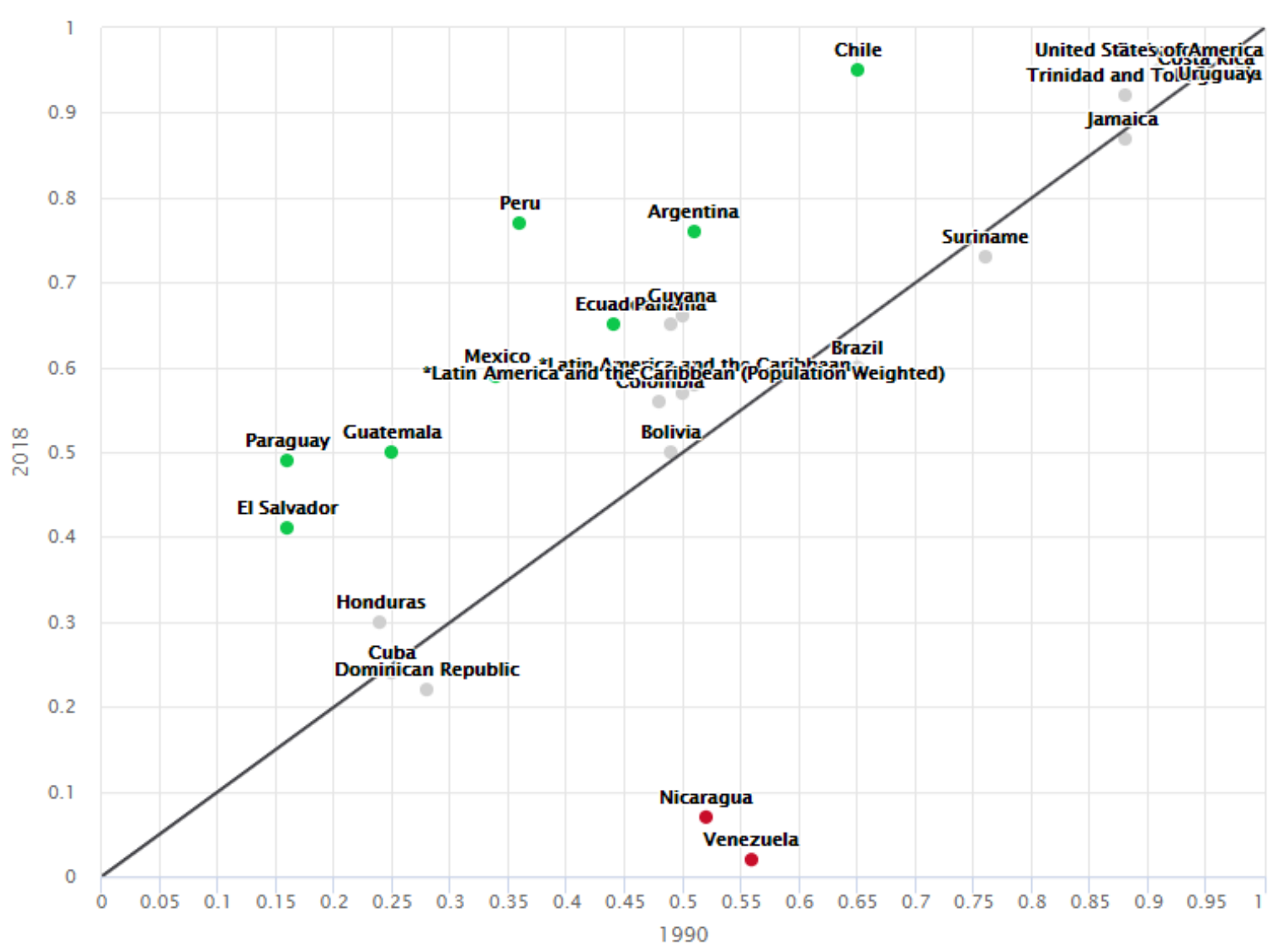

Fonte: Variedades de Democracia (1990 - 2018).

usando para isso indicadores que medem as atitudes, valores e comportamentos. Sítio: http://www.latinobarometro.org/lat.jsp.

${ }^{6}$ Componentes que fazem parte do índice do Estado de direito: acesso à justiça para homens e mulheres; suborno envolvendo executivos; trocas corruptas no setor público; accountability judicial; respeito pela constituição por parte do executivo; administração pública rigorosa e imparcial; decisões da baixa e alta corte em conformidades; independência dos tribunais regionais; independência da alta corte de justiça. 
No gráfico 2 observamos que Venezuela e Nicarágua apresentavam em 1990 índices melhores que o de países como Argentina, Bolívia e Equador. Todavia, ambos declinaram e em 2018 são os que detêm os menores índices de Estado de direito entre os países das Américas, 0.02 e 0.07, respectivamente. Para efeito de comparação, o Canadá tinha 0.98 em 1990 de índice de Estado de direito, e em 2018 apresenta 0.97. É o melhor Estado quando comparado com os demais. Em 2018 Uruguai e Costa Rica apresentam os melhores índices de Estado de direito entre os países latino-americanos, com 0.94 e 0.97 , respectivamente.

Estes argumentos e a sua base empírica trazem resultados importantes, mas isolados não podem justificar que a cultura latino-americana constitui causalidade central para uma baixa capacidade de Estado, pois que zonas culturais diferentes também têm apresentado problemas similares. Problemas de capacidade de Estado e déficits democráticos são cada vez recorrentes também em países denominados de capitalismo avançado (Norris, 2012). A crise atual do modelo liberal de democracia é bem mais complexa e provoca uma reviravolta na discussão de que existiriam culturas "melhores" ou mais receptivas para com este tipo de regime.

\section{Estaríamos condenados ao atraso e a instabilidade?}

Pelo que foi exposto nas linhas precedentes, podemos discernir e apontar para a existência de uma agenda que se tornou hegemônica e ainda contém traços normativos fortes escamoteados sob um discurso científico. A prosperidade e um regime democrático estável constituiriam exclusividade de países protestantes do Norte, enquanto que nações do Sul estariam condenadas ao atraso. Países latino-americanos sucumbiriam entre alternâncias de períodos democráticos e momentos de fechamento e autoritarismo, nunca conseguindo se livrar completamente os caracteres genéticos de clientelismo, patrimonialismo e populismo. Para o bem e para o mal, estes males, antes considerados apenas características presentes em sociedades atrasadas, começaram a despontar e a preocupar também democracias chamadas consolidadas.

Alguns eventos recentes forçaram uma guinada na agenda de pesquisas em direção a temas como populismo, personalismo e o nacionalismo ou neonacionalismo. $\mathrm{O}$ desdobramento desses eventos replica características similares em países tanto de democracias consolidadas quanto de democratização recente. A eleição de Donald Trump do Partido Republicano (GOP) nos Estados Unidos, o Brexit no Reino Unido, o fortalecimento da Frente Nacional da Marie Le Pen na França, e da direita mais radical na Polônia, na Hungria e, de um modo mais geral em toda a Europa, além da ascensão de lideranças com 
características assumidamente autoritárias como Recep Erdogan na Turquia, Rodrigo Duterte nas Filipinas e Jair Bolsonaro, no Brasil, são alguns eventos que forçaram a mudança da agenda de pesquisas. A mudança da concentração do poder político do centro para a direita e extrema direita forçou - inclusive por ocorrerem em centros importantes de exportadores de agendas de pesquisas - um olhar científico mais atento a fenômenos que antes eram estudos designados de países em desenvolvimento tardio ou que procuravam consolidar seus regimes democráticos.

O populismo constitui um bom exemplo dessa guinada na agenda, pois enquanto o fenômeno era restrito a países considerados de capitalismo tardio, subdesenvolvidos ou politicamente instáveis, o fenômeno fazia parte da periferia da agenda hegemônica institucionalista e culturalista, e quando era por estas abarcadas possuía vieses normativos e análises subjetivas. Gino Germani (1978) e Torcuato Di Tella (1965), por exemplo, entendiam o populismo como fenômeno de transição entre uma sociedade atrasada para uma moderna. Hoje, com o populismo de direita penetrando os regimes democráticos europeus, tendo presença forte na administração de Donald Trump, Estados Unidos, e o próprio movimento que levou ao Brexit, ele deixa aos poucos de ser tratado de maneira periférica e subjetiva para penetrar na agenda de forma mais objetiva.

Como trouxe Castells (2018), a crise do modelo liberal de democracia é um fenômeno global que tem atingido diversos regimes em muitos países. E uma agenda de pesquisas mais ampla deve reconhecer que os problemas que a democracia vem apresentando não se restringem apenas a democracias da terceira onda, mas está presente também em nações consideradas exportadoras do modelo liberal de democracia como Estados Unidos e Inglaterra. Os governos da conservadora Theresa May ${ }^{7}$ para a Inglaterra e Reino Unido e do republicano Donald Trump nos Estados Unidos, dois dos principais modelos de democracia liberal no mundo hoje passam um recado de claro retrocesso democrático ${ }^{8}$ ao fecharem suas nações diante da necessidade de resolução de problemas mais amplos como imigração, epidemias e aquecimento global, além do recorrente aumento nos constrangimentos legais para minorias e estrangeiros.

\footnotetext{
${ }^{7}$ No momento em que este artigo está sendo escrito, cresce o movimento de pessoas que pedem por um novo referendo pela permanência ou não da Grã-Bretanha na União Europeia. Ver: https://bit.ly/2QBwZha e https://econ.st/2DESnuw disponível em 18/12/2018.

${ }^{8}$ Ao contrário do que previa alguns analistas, a ideia de Donald Trump de construir um muro na fronteira com o México não constituiu apenas em um recurso estilístico em sua plataforma de campanha, sendo que o então presidente tem procurado constantemente apoio para tal iniciativa.
} 
Paralelamente à deterioração da arquitetura democrática, tem ocorrido também uma queda no apoio político por parte das massas, ou seja, uma piora na percepção dos cidadãos comuns em relação ao regime democrático. Tem aumentado a insatisfação com o funcionamento da democracia em muitos países, levando a caracterizações de "democracias insatisfeitas" (Pharr; Putnam; Dalton, 2000); o declínio da confiança em instituições que formam o cerne do modelo de democracia liberal como partidos políticos e parlamentos tem se aprofundado (Norris, 1999, 2011; Catterberg; Moreno, 2006; Wike; Fetterolf, 2018); e até mesmo um processo inicial de queda na adesão aos valores da democracia entre os mais jovens tem aparecido em pesquisas recentes (Foa; Mounk, 2016, 2017). Tudo isso acontecendo tanto em democracias da terceira onda quanto em nas consolidadas. Se a preocupação em alguns estudos a agenda está restrita à questão da arquitetura institucional democrática, em outros ela foca na crise dos valores e insatisfações com o funcionamento democrático. As duas dimensões tem implicações importantes para se entender a crise democrática atual.

Por isso, argumentamos que a instabilidade política não pode estar relacionada, apenas, a cultura política, pois até mesmo culturas protestantes, subentendidas como "melhores" ao longo do processo de formação e hegemonia da agenda de pesquisas nesse campo, hoje sofrem com ela. Qual o alcance explicativo, então, da cultura política para a instabilidade política contemporânea na América Latina? Podemos dizer que cada vez menor. Mas em que medida? Este é um campo a ser explorado por uma agenda nova que olhe para os problemas da região sem anuência de carga normativa e de forma mais objetiva, com o desenvolvimento de técnicas de pesquisa e elaborações conceituais específicas para cada região.

A teoria pós-materialista constitui um bom exemplo dessa limitação a que uma nova realidade mundial tem posto como desafios a agenda de pesquisas. No início da década de setenta, Ronald Inglehart ao publicar The Silent Revolution in Erope (1971) levantou a tese de os valores das populações de países da Europa Ocidental do pós-Segunda Guerra Mundial estavam transitando entre o que ele denominava de valores materialistas para valores pósmaterialistas, ou seja, valores que buscavam em primeiro lugar uma segurança material substancial estavam cedendo espaço para valores que, por sua vez, buscavam a emancipação e a autoexpressão humana como manifestações de vida. Estes valores eram os mais compatíveis com a democracia como regime político e podia explicar também sua estabilidade.

Apesar de Inglehart (1988) observar que as culturas são relativamente duradouras, mas não imutáveis, sua teoria não pode passar despercebida como de que estes países possuíam as 
democracias mais estáveis porque possuíam uma cultura política mais compatível ou "melhor". Hoje, no entanto, a realidade é bem diferente. Foa e Mounk (op. cit.) encontraram um processo inicial de desconexão por parte dos mais jovens para com a democracia e a Europa está mergulhada numa crise política que vai muito além da ideologia. Inglehart (2016), todavia, argumentou que não devemos nos preocupar, pois que esta crise é resultado de crescente vácuo na segurança existencial destas sociedades. Quer dizer, quando a democracia é estável, é porque há níveis de segurança existencial e valores de expressão que a sustentam, e quando não é estável faltam estes requisitos. Dizer isso é explicar pouca coisa para a atual crise da democracia liberal, e também é nada explicar sobre a estabilidade de regimes na América Latina.

É preciso questionar a episteme estabelecida e buscar novas explicações para a relação entre cultura política e democracia na América Latina. A perda relativa da capacidade explicativa de teorias culturalistas como o pós-materialismo de Inglehart deve estimular a transformação da agenda de pesquisa em cultura política, com o objetivo de retirar-lhe a carga normativa disfarçada sob o verniz do discurso científico. Esta não é uma tarefa fácil, mas vendo suas sociedades assoladas por fenômenos como populismo, personalismo e o nacionalismo, além de uma crescente descrença da sociedade em relação ao sistema político, talvez cientistas sociais destes países possam abrir suas caixas de ferramentas para repensar suas teorias aplicadas a eventos domésticos ao invés de continuar a expandir suas colonização epistemológica para as demais academias.

\section{Repensando a questão da cultura política para as democracias Latino-Americanas}

Se durante o século XX a agenda de pesquisas sobre a relação entre cultura política e democracia fora claramente normativa e desfavorável para países latino-americanos, recebendo críticas que não estavam além da forma metodológica e pouco penetrava num debate mais conceitual, hoje, ocorre algo bem diferente. A inflexão que hoje ocorre na agenda de pesquisas decorre principalmente do fato de que fenômenos como o populismo, personalismo e a volta do nacionalismo, antes atribuídos a sociedades desorganizadas e com crescimento econômico tardio e protecionista, penetram cada vez mais em países denominados de democracias consolidadas.

É importante destacar, ao contrário do que dá a subentender as análises procedimentais, que a democracia não é um regime unilinear. Como lembrou Dahl (2016), práticas democráticas sempre estiveram presentes nas mais diversificadas culturas. Essas práticas geralmente continham certo sentimento de igualdade política, respeito a regras e 
normas do grupo e buscavam harmonizar a vida em comunidade. Foi com o surgimento da democracia representativa, uma verdadeira "invenção" nas palavras de LeFort (1987), que um regime antes aristocrático vai aos poucos sucumbindo à ideia de igualdade política, mas não antes sem restringir esta às urnas através da fórmula um homem um voto. Um povo se autogovernando, a naturalização desse discurso começou a ganhar as principais nações da Europa e é o regime adotado pelos Estados Unidos da América, uma ex-colônia inglesa recém-emancipada e protestante.

O argumento do hibridismo cultural, da formação dos Estados e das sociedades latinoamericanas somados ao da capacidade de Estado precisam ser relativizados, pois tanto sozinhos ou em conjunto não explicam a razão da estabilidade ou instabilidade de um regime democrático. Como vimos nos gráficos 1 e 2, países como Uruguai e Costa Rica apresentam indicadores iguais ou até melhores de institucionalização democrática e capacidade do Estado (Estado de direito) que países como Estados Unidos e Canadá, de matrizes protestante. Até pouco tempo Lipset (1967) argumentava que eram necessários uma soma de 6 mil dólares per capta para a democracia pudesse ocorrer em um país de forma satisfatória, e a Índia até então tem provado o contrário. Moore (1983) fazia alusão de que somente sociedades nas quais houvessem ocorrido revoluções burguesas que tivessem realizado alterações violentas na sociedade, com uma ruptura forte, é que emergiria a moderna democracia industrial. E então temos o Japão, Coreia do sul e Taiwan com democracias até aqui se saindo bem em culturas confuncianas, mais verticais.

Pensar que apenas sociedades protestantes, ou aquelas que tiveram um período longo de formação de seus Estados são mais receptivas para com a democracia como regime político é atribuir-lhe uma carga normativa da qual a ciência política, hoje, está longe de sustentar nos fatos apresentados pela realidade. É verdade que a democracia liberal representativa teve como formação principal sociedades com características culturais desse genótipo, mas nem por isso podemos atribuir uma linearidade nesse desenvolvimento.

Novos caminhos explicativos passam pela compreensão das falhas do desenvolvimento da cidadania na região. Uma cidadania que promova a liberdade substantiva do indivíduo (Sen, 2000). O reconhecimento dos entraves sócio-históricos deve ser apreendido, mas deve ser colocado sob a mesa ao lado de uma pluralidade de fatores explicativos. Weber (2006) já chamava a atenção para a natureza pluricausal dos fenômenos sociais, pois que dificilmente são explicados por uma causa ou circunstância apenas. As falhas na aplicação de uma educação democrática, de conhecimento e consciência dos cidadãos de seus problemas decorrem, sim, de uma sociedade fragmentada, formada antes por 
um Estado e não como progenitora deste, mas dizer isto é explicar pouca coisa. É dizer que esse caminho chega a um só fim, o de um sistema político pouco estável, o que não constitui fato científico incontroverso.

Até aqui a ciência política moderna pouco reverberou que a democracia está para além do modelo liberal representativo e pouco destacou suas transformações ao longo do tempo. Experimentos de práticas de democracia direta vêm sendo testadas em diferentes níveis em alguns países. O Orçamento Participativo, como citou Schmitter (2015) é relacionado como um bom exemplo dessa ferramenta moderna. O financiamento público de campanha igualmente. Há certa presunção de que o modelo liberal de democracia seja o melhor, e a América Latina pode muito bem dizer que este modelo aqui aplicado tem gerado resultados aquém do esperado. Os avanços chegam ao nível procedimental, mas não atingem o conteúdo nem creditam qualidade à democracia praticada na região. Mas isso ocorre não porque temos uma cultura "inferior", e sim por que é um modelo aplicado a realidades diferentes em contextos sócio-históricos não lineares e que, portanto, não pode julgar-lhe a superioridade ou inferioridade.

Uma agenda de pesquisas com ferramentas e técnicas que se tornou hegemônica formando o que Shweder (2002) chamou de "mapa moral" das culturas, promovendo a expansão e afirmação cultural de países protestantes e ricos deve ofuscar cada vez menos análises objetivas, uma vez que a crise do modelo liberal de democracia se generaliza. Rupturas estão sendo feitas, mas ainda é muito cedo para dizer se haverá uma quebra de paradigma que faça desmoronar a epistemologia tradicional, ainda muito normativa quando o objeto de estudo é a relação entre cultura e democracia.

\section{Conclusões}

A existência do argumento de "culturas melhores" ou mais adaptativas a certos regimes que outras vêm sendo reforçado constantemente pela dominação do homem, instituições, ideologias e países. Ao longo do desenvolvimento da democracia representativa e a subsequente agenda de pesquisas na área da cultura política que ganharam fôlego em meados do século XX, houve um grande esforço para qualificar culturas protestantes como mais receptivas à democracia. A chave explicativa girava em torno de essas culturas serem mais participativas na vida política da comunidade, de possuírem maior confiança interpessoal, social e institucional, e de pertencerem a Estados capazes, ou seja, Estados que se formaram ao longo de um processo lento e conflituoso em direção a maiores capacidades de arrecadação e coerção. 
$\mathrm{O}$ argumento da epistemologia tradicional da cultura política mostra claramente um esgotamento. É preciso, portanto, reconhecer seus limites ao justificar a existência de relação causal entre cultura política e instabilidade democrática na América Latina. Obras clássicas de formação acadêmica sobre a região da América Latina vêm perdendo cada vez mais seu poder explicativo em razão de uma realidade cada vez mais complexa e em trajetórias que não tinham sido delineadas nessas teorias. Democracias consolidadas sofrem cada vez mais com o populismo, o personalismo e a corrupção endêmica. Estes fenômenos, uma vez que passaram a estarem mais presentes em países desenvolvidos, forçaram a agenda de pesquisas da cultura política a reconhecer e reavaliar métodos e conceitos antes usados comparativamente de forma indiscriminada.

As pequenas rupturas feitas no coração dessa epistemologia tradicional já dão conta de que, tanto o tipo de cultura quanto a forma de transplantes de modelos de democracia, além da capacidade de Estados, devem ser relativizados quando procuramos encontrar uma relação entre cultura política e estabilidade democrática. Em outras palavras, a cultura não determina as chances de sucesso ou não de um regime democrático, mas sim, ajudam a entender a formação democrática sob as mais variadas culturas. Até pouco tempo, houve cientistas sociais dizendo ser impossível uma democracia em países como a Índia, culturalmente diversificado e pobre.

Como trazido por este trabalho, novos caminhos explicativos passam pela compreensão das falhas do desenvolvimento da cidadania na região, que por sua vez não precisa necessariamente ser linear, mas sim atingir certo grau de maturidade civil, política e sensibilidade social. Os entraves sócio-históricos não determinam as democracias da região, mas falhas na aplicação de uma educação democrática de conhecimento, reconhecimento e consciência dos cidadãos de seus problemas parecem problemas recorrentes nos regimes latino-americanos. E a estabilidade política da região passa, necessariamente, por estes fatores.

\section{Referências}

ALMOND, G; VERBA, S. The civic culture: political attitudes and democracy in five nations. Princeton: Princeton University Press, 1966. 349 p.

BADIE, B; HERMET, G. Política comparada. México: Fondo de Cultura, 1993. 319 p.

BANFIELD, E. C. The moral basis of a backward society. Glencoe: The Free Press, 1958. $188 \mathrm{p}$. 
BAQUERO, M. A desconfiança como fator de instabilidade política na América Latina. In: ; CASTRO H. C. O.; GONZÁLEZ R. S (Orgs) A construção da democracia na América Latina. Porto Alegre/Canoas: UFRGS/Centro Educacional La Salle, 1998. P. 13-29.

- Qual democracia para a América Latina?: capital social e empoderamento são a resposta?. Porto Alegre: Editora da UFRGS, 2013. 160 p.

CASTELLS, M. Ruptura: a crise da democracia liberal. Rio de Janeiro: Zahar, 2018. 152 p.

CASTRO, H. C. Cultura política comparada: Brasil, Argentina e Chile. Brasília: Verbena, 2014. $140 \mathrm{p}$.

CATTERBERG, G; MORENO, A. The individual bases of political trust: trends in new and established democracies. International Journal of Public Opinion Research, Oxford, v. 18, n. 1, p. 31-48, 2005.

DAHL, R. A. Sobre a democracia. Brasília: Editora Universidade de Brasília, 2016. 230 p.

DI TELLA Torcuato. Populismo y reforma en América Latina. Desarrollo Económico, v. 4, n. 16, p. 391-425, abr-jul, 1965.

FOA R. S.; MOUNK, Y. The democratic disconnect. Journal of Democracy, V. 27, n. 3, p. 517, July, 2016.

The signs of deconsolidation. Journal of Democracy, v. 28, n. 1, p. 5-15, jan., 2017.

FUKUYAMA, F. Why democracy is performing so poorly? Journal of Democracy, v. 26, n.1, p. 11-20, 2015.

GERMANI G. Autoritarianism, fascism and national populism. New Brunswick: Transaction Books, 1978. 292 p.

HUNTINGTON, S. P. A ordem política nas sociedades em mudança. Rio de Janeiro: Forense-Universitária. São Paulo: Ed. da Universidade de São Paulo, 1975. 496 p.

. A Terceira Onda: A Democratização no Final do Século XX. São Paulo: Ática, 1994. $335 \mathrm{p}$.

A importância das culturas. In: LAWRENCE, E. H.; HUNTINGTON, S. P. A cultura importa: os valores que definem o progresso humano. Rio de Janeiro: Record, 2002. P. 11-15.

INGLEHART, R. The silent revolution in europe: intergerational change in pos-industrial societies. American Political Science Review, v. 65, n.4, p. 991-1017, dec., 1971.

. The renaissanse of political culture. The American Political Science Review, v. 82, n. 4, p. 1203-1230, dec., 1988.

Cultura e democracia. In: LAWRENCE, E. H.; HUNTINGTON, S. P. A cultura importa: os valores que definem o progresso humano. Rio de Janeiro: Record, 2002. P. 133153. 

2016.

How much should we worry?. Journal of Democracy, v. 27, n. 3, p. 18-23, July,

; WELZEL, Christian. Modernização, Mudança Cultural e Democracia: e sequencia do desenvolvimento humano. São Paulo: Francis, 2009. 400 p.

LANDES, D. Quase toda a diferença está na cultura. In: LAWRENCE, E. H.; HUNTINGTON, S. P. A cultura importa: os valores que definem o progresso humano. Rio de Janeiro: Record, 2002. P. 39-52.

LEFORT, C. A invenção democrática: os limites da dominação totalitária. São Paulo: Ed. Brasiliense, 1987. 247 p.

LEVITSKY, S. Democratic survival and weakness. Journal of Democracy, v. 29, n. 4, p. 102113, oct, 2018.

LIPSET, S. M. O homem politico. Rio de Janeiro: Zahar, 1967. 440 p.

MOORE, J. B. As origens sociais da ditadura e da democracia. São Paulo: Martins Fontes, $1983.589 \mathrm{p}$.

NORRIS, P. Critical citizens: global support for democratic governance. New York: Oxford University, 1999. $303 \mathrm{p}$.

Democratic deficit: critical citizens revisited. Spring: Cambridge University, 2011. $335 \mathrm{p}$.

Making democratic governance work: the impact of regimes on prosperity, welfare and peace. New York: Cambridge University, 2012. 281 p.

O’DONNELL, G; SCHIMITTER, P; WHITEHEAD, L. Transições do regime autoritário. São Paulo: Vértice, 1988. 127 p.

PHARR, S. J.; PUTNAM R. D.; DALTON, R. J. A quarter-century of declining confiance. Journal of Democracy, v. 11, n. 2, p. 5-25, 2000.

SCHMITTER, P. C. Crisis and transition, but not decline. Journal of Democracy, v. 26, n. 1, p. 32-44, 2015.

SEN, A. Desenvolvimento como liberdade. São Paulo: Companhia das Letras, 2000. 411 p.

SHWEDER, R. A. Mapas morais, presunções de "primeiro mundo" e os novos evangelistas. In: LAWRENCE, E. H.; HUNTINGTON, S. P. A cultura importa: os valores que definem o progresso humano. Rio de Janeiro: Record, 2002. P. 231-251.

SILVA, F. P.; BALTAR, P.; LOURENÇO, B. Colonialidade do saber, dependência epistêmica e os limites do conceito de democracia na América Latina. Revista de estudos e pesquisas sobre as Américas, v. 12, n. 1, p. 68-87, 2018. 
TILLY, C. Coerção, capital e Estados europeus. São Paulo: Edusp, 1966. 356 p. Democracia. Rio de Janeiro: Vozes, 2013. 256 p.

TOCQUEVILlE, A. A democracia na América. Belo Horizonte: Itatiaia, 1987. 600 p.

WEBER, M. A ética protestante e o espírito do capitalismo. São Paulo: Pioneira; Brasília: Ed. da Universidade de Brasília, 1981. 234 p.

Ciência e política: duas vocações. São Paulo: Martin Claret, 2006. 128 p.

WIKE, R.; FETTEROF, J. Liberal democracy's Crises of confidence. Journal of Democracy, v. 29 , n. 4 , p. $136-150$, oct., 2018. 